\title{
LEARNING FROM RENEWAL PROJECTS: CONTENT, CONTEXT AND EMBEDDEDNESS
}

\author{
by \\ Tomas Blomquist and Johann Packendorff \\ Umeå School of Business and Economics, Dept of Business Administration, Umeå \\ University, S-901 87 UMEÅ, SWEDEN. \\ Phone: +469078677 22/+469078678 71, Fax: +469078666 74, \\ Email: Tomas.Blomquist@Fek.UmU.Se/Johann.Packendorff@Fek.UmU.Se
}

Blomquist, T. \& Packendorff, J. (1998) "Learning from Renewal Projects: Content, Context and Embeddedness." In: R. A. Lundin \& C. Midler (eds.) Projects as Arenas for Renewal and Learning Processes. Norwell, MA: Kluwer: pp. 37-46.

\begin{abstract}
During the last decade, there has been an increasing awareness on the importance of òembeddednessò as an important dimension in analyzing projects. While traditional project management theory presupposes that projects are clearly defined and separable from the context in which they are implemented, the notion of embeddedness implies that contextual factors affect the project organization throughout the whole project. In the most embedded kind of projects, renewal projects, most actions are in fact taken with the learning context in mind rather than the project contents.

One way of analyzing embeddedness in project management is to make use of the insights of strategic issue management theory, proposing that the context of upcoming strategic issues in organizations is crucial for the understanding of how these issues are managed.

From an analysis of a case study of a òtest-projectò in Swedish health care, project management and learning in embedded projects is discussed. Project management theory can be used to reduce contextual complexity and to make project participants focusing on project contents, but it should be complemented with a strategic issue management approach in order to make use of the complexity and having the project context consciously managed.
\end{abstract}

\section{THE NOTION OF EMBEDDEDNESS IN PROJECT MANAGEMENT}

This chapter is an attempt to analyze renewal projects as instances for organizational learning. The point of departure for the analysis is that such projects are extremely embedded. In the analysis, we will use insights from Strategic Issue Management theory in order to gain a better understanding of projects as socially constructed issues in permanent organizations.

The Project and its Context. 
One of the fatal mistakes of early organizational theorists such as Taylor, Fayol and others, was to view organizations as closed activity systems that could be designed for optimal effectiveness and maintained with simple managerial practices. But research has pointed out that organizations cannot be understood unless their context is understood. Organizations are embedded in a complex societal web of people, resources, institutions, market conditions, and the activities inside them are always affected by the characteristics of that web (cf Granovetter, 1985).

In many important ways, traditional Project Management theory still suffers from the rationalistic dreams of the early 20th century (Buchanan, 1991; Packendorff, 1995). It is based upon a perception of the project as a distinct, manageable activity system that, once having been designed using the proper scheduling techniques, can be isolated from the environment and implemented. The environment only exists before and after the project, providing goals and resources and receiving the final result.

Researchers pursuing this view have, however, noticed that projects are actually dependent upon their environment throughout their life cycles do have an environment throughout their life cycle (cf Pinto \& Prescott, 1988, 1990). In recent literature, this notion has been investigated further. Departing from an alternative view of project environments a number of studies has been made on how different sorts of environmental factors affect project organizations (Buchanan, 1991; Borum \& Christiansen, 1993; Kreiner, 1995; Pinto, 1996). Empirical examples of the consequences of project embeddedness are also to be found (Ekstedt, Lundin \& Wirdenius 1992; Hellgren \& Stjernberg, 1995; Kadefors, 1995; Midler, 1995). Løwendahl (1995) has referred to this in terms of projects being embedded in their environment.

\section{Project Content and Project Context.}

The common denominator of these observations can be expressed in terms of what Hodgetts (1968) called the project managerôs Òauthority gapò, i.e., the gap between the full responsibility for project outcomes and the incomplete authority over the resources needed for reaching those outcomes. One perspective of this gap is concerned with formal authority of the project manager, where embeddedness implies that executives in the surrounding permanent organization reserve the right to put the project managerôs operative decisions in question. This structural restriction has been observed by many scholars (cf. Jessen, 1992: 73f; Midler, 1995).

Another perspective consists of an extended view of project effectiveness; if the project manager finds himself in a situation where he has to choose between a scheduled activity and an activity proposed by the customer, he must act so that the customer still find the project to be an effective one. Frame (1994: ch. 5) describes customer orientation as something both project management professionals and their customers must learn, and he states (p. 107) that òthe project management process is a grand exercise in compromise, from defining needs all the way up to writing the final documentation at the conclusion of the projectò.

A third, and the most important, perspective on the authority gap is the conceptions of project participants concerning the status of the project. In embedded projects, most team members have positions in the surrounding permanent structure and they also refer to that structure in terms of social/cultural belonging and career paths. The more embedded the project is, the harder it is to identify the actual borders of the project organization and the harder it is to gain 
commitment to the project from project members. Project members will act depending on how they perceive the project and what they expect from it, not necessarily according to project plans, effectiveness criteria or formal structure.

From a traditional Project Management point of view, embeddedness is a dysfunction. Projects are supposed to be closed activity systems in order to be possible to manage effectively, and all environmental influences are consequently seen as disturbances that the project manager has to protect his organization from. There is only one reality (i.e., the one of the project manager), and differences in how people inside or outside the project perceive it must be brought to convergence.

Another way of handling embeddeness is to take contextual complexity and multiple perceptions for granted, and thus to find ways to define and handle environmental influences to the benefit of both the project and the surrounding organization(s). This is a view of projects as political issues on the organizational agenda rather than as closed activity systems construed out of corporate goals, issues that need to be piloted trough the organization while satisfying all relevant stakeholders.

Types of Project, Degree of Embeddedness.

One way of distinguishing between degrees of embeddedness is to analyze how people in projects perceive the project organization and how they perceive themselves in relation to the project organization. The less discernible the project structure is vis-à-vis other structures and the less tied the individual is to it, the more embedded it is. Applying the categorization in Packendorff (1994: 216f) as a point of departure, different types of projects could be identified as having different degrees of embeddedness. The theoretical ideal project, the òtask forceò, is not embedded at all; the environment states the task from the beginning and receives the result in the end. Other forms, such as projects as temporary matrix organizations or action groups, are more embedded in their environment but still also delimited from it.

The type of projects analyzed in this chapter, i.e. organizational renewal projects, are usually different from other projects in that it seldom implies an explicit task structure and that most people in the organization will stay full-time in their permanent positions during the project (cf. Briner \& Geddes, 1990). The ones advocating and carrying through the renewal project is in fact those who find the renewal worthwhile, an opinion not necessarily grounded in any formal position in either the permanent organization or the renewal effort. At the same time, many of the attributes usually ascribed to project work is still there, such as time limits, complex and/or interrelated tasks, success criteria and so forth (McElroy, 1996; Partington, 1996). The degree of embeddedness might, however, be so high that while top management defines and promotes the project explicitly, people at the òshop floorò might misinterpret the issue at stake or devoting their energy to entirely different issues (cf. Blomquist, 1994; Ekstedt \& Wirdenius, 1995).

\section{EMBEDDEDNESS AND ORGANIZATIONAL LEARNING}

\section{Level of context.}


One way of establishing a Project Management theory on learning in renewal projects grasping the complexity arising from their embeddedness could be to relate to theories on strategic change in organizations. The theory proposed here is the Strategic Issue Management theory as described by Jane E. Dutton and her colleagues (cf. Dutton \& Duncan, 1987; Dutton, Stumpf \& Wagner, 1990; Dutton, 1993). According to Dutton, strategic management in organizations is in fact the continuous processing of upcoming issues on the organizational agenda, issues perceived as having a strategic importance for organizational performance and consequently also as important instances for learning. It should be noted that òissuesò are not necessarily òproblemsò, and that they are not necessarily òdecisionsò (Dutton, Stumpf \& Wagner, 1990). Examples of strategic issues in a health care organization could thus be new methods for medical treatment, a new administrative structure, complaints from nurses on low salaries or equal opportunity legislation.

A central observation in strategic issue management theory is that the processing and impact of an individual issue have quite little to do with the contents of the issue, i.e., the actual problem, opportunity, plan, solution or opinion at hand. Instead, the understanding of how a strategic issue is processed through an organization must be sought in the context of the issue. Issues are interpreted differently by different actors inside or outside the organization, and managing a strategic issue is thus in fact managing peopleôs perceptions of it. Dutton (1993) describes three levels of context that are important to the interpretation and processing of an issue:

AThe issue context, i.e., (1) the individuals proposing/managing the issue and (2) the organizational arena into which the issue is brought. If the people that define and call attention to the issue is seen as reliable, powerful and trustworthy, then they are likely to be able to gain consensus around their definition and have the issue being interpreted as an opportunity throughout the organization. They also have to find the proper arena for the issue, i.e., a social forum where the major stakeholders in the issue are represented and where the necessary support for maintaining the issue can be gained. The arena could be a formal forum (e.g., an executive committee or a board), but could also be more informal by nature (e.g., Rotary meetings or coffee breaks).

$\AA$ The organizational context, i.e., (1) organizational culture, (2) the current strategic agenda, and (3) the capacity of the organization to initiate and process further issues. Strategic issues that are not compatible to the ideas, world-views and symbols taken for granted in the organization are not likely to survive for very long, and the proponents of an issue must therefore make sure that it òfitsò with central values in the organization. The issue must also fit into the current strategic agenda; from time to time. Earlier issues are part of the history, and set constraints for what new issues that could take place. In e.g. a period of perceived scarcity and downsizing, issues containing bold and costly ventures are likely to receive low priority and to be unsuccessfully implemented even if they are in line with the firmôs long-term plans. And even if the time is right, there might be a number of other strategic issues under investigation and implementation in the organization, thereby in fact making it impossible to raise any further issues. The more centralized and top-down oriented the organization, the smaller the managerial capacity to deal with upcoming strategic issues. 
ÅThe institutional context, i.e., (1) important issues in society and/or the industry and (2) the perceptions of environmental stability/instability. Strategic issues are not subject to intra-organizational constraints only, they are also constrained by the culture and the conventional wisdom of industry and society. The well-known notion of isomorphic processes by which organizations are becoming increasingly alike by means of coercion, normative regulations and imitation (DiMaggio \& Powell, 1983: 150ff) is an example of such constraints. Issues perceived as challenging whole occupational professions is thus hard to implement, and so are issues implying that people should act differently from what they feel is expected from them by societal norms. Connected to this is also the perception of dynamism and change in the industry and/or society, in that it sets the pace and sense of urgency for decision and implementation of strategic issues.

\section{CASE STUDY: THE PPM TEST-PROJECT IN ONETOWN}

During some years in the beginning of the 1990ô,, market-oriented organizational models had a great influence on the public sector in Sweden. It became common to organize, distribute resources, control and manage public-owned organizations by a provider/purchaser-model. In this model, the organization is divided into two parts; one group that provide services to the citizens and one group that purchase these services from different providers as representatives of the citizens.

\section{The test-project.}

Like many other county councils (tax-financed, politically governed regional organization responsible for health care, dental care etc.) in Sweden, the County Council of Uptown decided that they had to change their organization and introduce the provider/purchaser-model. After some political arguments it was decided that the model should be subject to a test-project for a limited time in one of the districts in the Uptown county in order to see if the learning results were satisfactory. The notion of the test-project were introduced since the project were to be evaluated after some years to see if the rest of the county should adopt the model.

In spring 1991, a small group of top executives at the Uptown headquarters prepared a proposal for a new health care organization in the county. Responding to a majority among the politicians in the council, they recommended that a project should start in order to test the provider/purchaser-model in a small part of the organization, namely the Onetown district in the southern end of the county. After some considerations, a decision was made that the new organization should start from January 1, 1992, and run for two years. No clear project plan was included in the proposal, and the practical arrangements had to be made after the decision. However, a number of other projects being processed at the same time consumed a lot of managerial resources at the Uptown headquarters, which made it impossible for the responsible managers to prepare and plan for the project. As a result, the whole test-project was delayed by one year and started January 1, 1993. The group that had made the initial investigation should help and support the Onetown people in implementing the test-project, in fact acting as project managers. But other upcoming projects made it hard for this group to focus on the test-project, and the 
purchasers and providers in Onetown was left almost on their own without any close management support.

The new organization took shape, but the first purchase agreement was delayed by half a year. The Uptown headquarters finally had to intervene to close the agreement between the providers at the Onetown hospital and the local purchaser board. The same conflicts and delays appeared the subsequent years, and the top managers in Uptown made the process subject to closer supervision.

In accordance with the plans, the same group that had initiated the test-project made an evaluation study. Evaluations were made from the beginning of the project until February 1994. Since the deadline of the evaluation study remained fixed despite that the test-project had been delayed by one year, it was hard for the evaluators to say anything specific on how the test-project had affected productivity, consumer satisfaction and overall performance in the Onetown district. Still, the politicians decided to implement the provider/purchaser-model in the rest of the Councilôs districts from January 1, 1996.

The actors in the test-project.

In 1991, the politicians and the executives at the Uptown headquarters were facing an economy in recession and a strong trend among other Swedish county councils to implement the provider/purchaser model. The main purposes for introducing the model in the organization were expressed as a need for improved local democracy and a conviction that the model should make the production of health care services more effective.

Among the top managers in the Uptown headquarters, emphasis was put on the democratic aspects of the model. The initial investigation was a part of their traditional report on the political organization preceding each general election, and the effectiveness arguments was thus attached to the model later on. The emphasis on local democracy implied that they were reluctant to interfere with the local negotiations and agreements, and upcoming competing projects led them to give the providers and purchasers in Onetown a lot of freedom in their discussions and agreements. This freedom were later restricted in a number of ways.

The local politicians and managers at the Onetown purchaser board felt unwanted and disliked by the providers. They were new in their profession, and they had very little experience and information as compared to the providers. Consequently, they appreciated that the providers took the initiative the first year and gave them an detailed offer. The drawback of this was that the purchasers were forced into a system where costs and production volumes became the topics of discussion, instead of quality issues and the needs of citizens and different patient groups.

The providers had to change some of their administrative routines in order to comply with the provider/purchaser-model, which annoyed them. The CEO of the hospital wanted the old system with annual budgets back, and resented the use of performance related pay to the Onetown hospital. The initial work on calculating costs and measuring productivity was left to the clinical heads, and the CEO launched issues like re-organizing the hospital into profit centers and having it certified as a òHealth Promoting Hospitalò by the World Health Organization. Hospital management soon found out that they in fact was the only provider of health care in the Onetown area, which meant that there could hardly be any competition with other providers. 
Many of the clinic heads worked very hard before the introduction of the provider/purchaser-model. The reason why they worked so hard were that they believed that if they did not present a proposal in time to the purchaser, they should loose all production the coming year. They also thought that their clinics could become small firms of their own in the future.

\section{THE TEST-PROJECT AS A STRATEGIC ISSUE}

The case of the test-project in Onetown shows that renewal projects are hard to analyze using the traditional Project Management set of theories and methods. While traditional Project Management theory presupposes clear-cut goals, a visible project structure and consensus on how the project is to be implemented, the testproject points at that renewal projects are perceived differently by different actors, that it is impossible to tell whom is actually in the project structure and whom is not, and that different individuals perceive different projects with different outcomes. Consequently, different actors expect to learn different things from the renewal project, which means that the project can not become a common learning experience for the organization.

One could say that the test-project is an example of yet another case of failure in organizational communication; if e.g. the CEO of the hospital had been more loyal to his superiors and more powerful vis-à-vis his inferiors, a higher degree of consistency and guided learning would have been found among the respondents. Adopting such a view, one could conclude that Project Management theory was right all the time, but that the actors in the organization failed to use it in the proper way. But what we would like to stress is that inconsistencies and multiple realities are a natural part of the daily life of most complex organizations, and that theoretical expectations on the implementation of renewal projects should take this into account (cf. Blomquist, 1994; Ekstedt \& Wirdenius, 1995). It is not that we consider Project Management theory to be basically wrong, we just would like to see different Project Management theories for different kinds of projects (cf. Packendorff, 1995: 324f; Partington, 1996: 20). By analyzing the test of the provider/purchaser-model as a strategic issue, a number of contextual factors constraining the likelihood of successful implementation can be identified:

\section{The issue context.}

Concerning the individuals that proposed/managed the provider/purchaser-model, we mostly find groups of persons but no single project leader. One such group is the politicians who decided that the test-project should be implemented in the first place. Another one is the group of central administrators that wrote the proposal on how the test-project and the model should work. Finally, we have the group of people in Onetown that almost without any guidance had to solve the practical problems during the test-project. In this heterogeneous group we have the purchaser board, the Onetown hospital administrators, and the clinic heads.

There was a tradition in the CCU that the top management in Uptown had been relatively weak and almost invisible to the people in the organization. Initially, the issue of the test-project in Onetown was handled in accordance with this tradition, but the conflicts between the purchaser board and the hospital management forced 
the CCU top management to intervene several times. When the provider/purchasermodel was to be implemented in the whole County Council, top management suddenly became visible and powerful, a development interpreted by many as a clear break with tradition.

There was also a tradition in CCU that new ideas should always be tested, but that these tests should be made in small parts of the organization. This meant that the test-project was in line with tradition, but also that no one really believed that the provider/purchaser-model was a serious reform that would make a difference. Most people in the organization knew that there were at least four or five other issues being handled during the period of the test-project. It was far from evident to the hospital management in Onetown that the provider/purchaser-model was the most important and urgent issue to deal with.

If we look at the organizational arena which the issue was brought into, we find that the Onetown district is quite different from the rest of CCU. One of the main differences is that the hospital of Onetown is much smaller than the University hospital of Uptown. The Onetown hospital had not really anything to gain from cooperating with the purchaser board, since their main competitive advantage was their geographical location. In terms of medical competence and economies of scale, Uptown would always be the best provider, and the best strategy for Onetown was thus to criticize the provider/purchaser-model rather than becoming a loyal part of it. Moreover, since the purchaser board did not have any additional resources as compared to the old budget, the model was not perceived as an opportunity. Instead, some of the significant actors at the hospital formulated a vision of the Onetown hospital as becoming a òHealth Promoting Hospitalò according to World Health Organization guidelines. The organizational arena was thus poorly managed and the only common understanding concerned the deadlines for the agreements and the whole test-project.

\section{The organizational context.}

Like the rest of the public sector, the County Council of Uptown had no previous experience in using market oriented management control models like the provider/purchaser-model. The òpolitical economismò inherent in the model is in sharp contrast to the culture of the majority of the employees in the County Council, i.e. medical doctors, nurses etc. Their main ambition is to cure patients and serve the citizens in the county, and they usually defend their hospitals and clinics against administrative and political initiatives. Since the provider/purchaser-model came to be introduced in a time of cost savings and downsizing, the culture clash was inevitable.

The current strategic agenda was vague, and had so been for a long time. The lack of top management initiatives in the past had created a situation where anything could be brought up into the strategic agenda as long as it contributed to the County Councilôs cost savings and downsizing ambitions. This meant that the strategic agenda was open to all new propositions, at the same time as there were no strategic vision at hand when selecting between upcoming issues. In such a context, the most important feature of an issue is strong and committed stakeholders being able to convince other influential people on the advantages of the issue.

Concerning the County Councilôs capacity to initiate and process further issues, we observed that most people in the organization were not motivated to handle any new issues or projects. They know that before they had implemented it, the plans 
would be changed and other issues would appear as more urgent or more popular among politicians and top managers. The need for peace and quiet will thus make it hard for initiators of new issues to implement these, even if there are formal decisions supporting them.

\section{The institutional context.}

The provider/purchaser-model was a part of the general trend in Western Europe to implement market oriented management control models in the public sector. Almost every Swedish county council planned or investigated the possibilities to introduce the model in the beginning of the 1990ô. It was so popular that those counties that did not follow the mass had to defend themselves against accusations of being conservative and old-fashioned. This was also (and still is) a time when most public authorities struggle with large budget deficits, so the pressure from citizens and the government to òdo somethingò increased rapidly. In such situations, it is easy to choose a legitimate solution in the environment and implement it to show that the problems are being dealt with.

Apart from the political and administrative fields, the county councils are also part of a medical community, where new methods and philosophies of treatment are developed independently of what happens in politics and economics. For example, one of the clinic heads in Onetown had a vast national network of leading medical doctors, and òimportedò medical issues to Onetown and the County Council the same way as the politicians and administrators brought the provider/purchaser-model there.

\section{LEARNING AND EMBEDDED PROJECTS}

From a traditional Project Management point of view, the test-project is a failure in many respects. Planning was inadequate, the task was not well defined enough, it was not clear who was responsible for the project, the project was disturbed during implementation, different individuals and stakeholders had different views of the project, and so forth. One could argue that consciously treating the test-project as a clearly defined project should have implied better prospects for success. If there had been a clear project plan, an appointed project manager with full responsibility and adequate control over project resources, and a shared image among participants and stakeholders on the goals and methods, then the test-project would have been more successful in terms of learning (cf. Morris \& Hough, 1987: ch. 11). True, indeed.

On the other hand, an analysis focusing on the management of the contents of the test-project would miss essential aspects needed for a full understanding of the situation. In this case, the mode of decision and implementation was not primarily a result of bad management practice, it was a necessary consequence of the contextual circumstances. The issue at hand (i.e. the provider/purchaser-model) had its origin in the institutional environment of the County Council, and found its way to Onetown since it was a politically legitimate system of local governance and resource allocation at the time. From the start, the implementation of the model became solution-oriented rather than problem-oriented, which implied that the managerial task was to gain and maintain support for the model rather than conducting a traditional problem-solving process. During implementation in 
Onetown, it became obvious that the provider/purchaser-model was not consistent with the local culture of independency vis-à-vis the Uptown headquarters, and that the strategic agenda in Onetown contained a number of other issues to be handled. From the Onetown hospitalôs point of view, the test-project is thus a failure which they wish could be removed from the agenda as soon as possible. But from the initiating part, i.e. the political and administrative executives in Uptown, the provider/purchaser-model has been a successful issue in the sense that it has been implemented according to their initial intentions. The remaining problems with the local culture and strategic agenda in Onetown do call for further managerial efforts, but they will never be entirely solved. The management of the test-project could thus have been better at the local level, by adapting it to the current strategic agenda and the cultural peculiarities at the hospital.

\section{Avoiding complexity, focusing on content.}

The test-project could thus have benefited from having been managed in a more structured and focused fashion. The complexity and lack of common learning resulting from the high degree of embeddedness could have been handled through trying to make the test-project more like a òpure task forceò. Even in less embedded projects, the effects of embeddedness is often disturbing; the problems of managing projects effectively in e.g. matrix structures (Hodgetts, 1968) or in temporary networks of permanent organizations (Hellberg \& Stjernberg, 1995) are well documented. Using project management theory in embedded projects is not only to apply a certain set of methodologies, it is to make the project a more explicit one by describing it and organizing it in terms of ideal projects. As stated above, most projects can not be managed as ideal projects, but one could still make use of the inherent imperatives in project management theory. Essentially, this means (1) avoiding complexity, and (2) focusing the content.

By Òavoiding complexityò, we mean Òavoiding all unnecessary complexityò. Complexity that stem from complicated organizational structures or an inability to state and communicate project goals could often be reduced through conscious managerial efforts. Clients and stakeholders with vague or non-existent ideas on project goals and methods should be required to formulate their thoughts into clear, unambiguous objectives. The borders of time and space surrounding the project should be as clear as possible in order to put mental òbracketsò (Lundin \& Söderholm, 1995: 446f) around the effort to be brought about.

The reduction of external and internal organizational complexity should make it possible for the people involved to focus on the contents of the project, i.e. defining and implementing the activities needed for achieving the objectives. Since many projects are not possible to design beforehand in the sense that a work breakdown structure can be established, one might at least try to identify milestones and/or points in time for re-evaluation and re-scheduling during the implementation phase (cf. Turner \& Cochrane, 1993). In accordance with Gersick (1988), we would suggest alternating periods of openness and closedness during the life-time of the project; moments of openness in order to ensure external relevance, and periods of closedness in between in order to enable the project organization to carry out the implementation activities. Like other organizations, projects need some sort of òbufferingò function in order to be able to operate in peace and quiet.

Making use of complexity, focusing on context. 
At the same time as project management theory is useful in reducing complexity and helping project participants to focus on their tasks, it is useless in embedded projects unless there exist a great deal of awareness concerning the tendency of organizations to handle such projects as strategic issues. Without conscious efforts to recognize and make use of the complexity and turbulence in the project environment, managers of embedded projects will face severe difficulties. The complexity that can not be reduced by means of traditional project management must be handled as an opportunity if the political process through which the project is implemented should be successful. According to strategic issue management theory, the project manager must establish a view of the project as related to other ongoing issues in the organization (Dutton, Stumpf \& Wagner, 1990) and maintain consensus on that the project is both feasible and urgent to deal with (Dutton \& Duncan, 1987) an that it is an opportunity for the organization not to be neglected (Dutton, 1993).

In organizations such as the County Council of Uptown and the Onetown district, the diversity in culture, institutional environments, professions etc. calls for a strategic issue management approach aiming at satisfying all stakeholders and participants. Different groups, organizational levels or professions must be convinced using different arguments, and they must be made to see their specific interests being looked after in the project. A project satisfying politiciansôneeds to install new principles of local government could e.g. at the same time satisfy administratorsôneeds for cost control and medical doctorsôneeds for professional autonomy. The project must have some sort of a vision shared by all, but at the same time different stakeholders must feel that there are goals in the project that is appealing just to them (cf. Christensen \& Kreiner, 1991). If the initiators of a project can reach such a shared but still diverse understanding of a project, then the complexity can be turned into a trigger for action and real learning.

As noted by e.g. Kreiner (1995), the context of projects should be managed in order to avoid òdrifting environmentsò. Beside keeping all stakeholders happy with the way the project is going (the usual notion of project context management), one must also keep it alive on the organizational agenda. Even if the stakeholders are satisfied, new issues/projects might arise on the agenda that seem even more attractive to all or some of them. The context of the project is thus in need for continuous management of how people perceive it in relation to other projects. Projects not threatening the present one could be attached to it, and projects in fact considered to be threats could be fought against or redefined into supportive/subordinate projects. Additionally, one might have to look outside the organization to find out if there are other possible issues in the institutional environment that are likely to find their way into the organization. If you do not come to the environment, the environment will come to you. And it is most likely to disturb you.

\section{REFERENCES}

Avots, I. (1969) òWhy Does Project Management Fail?ò California Management Review, Vol 7, No 1: pp. 77-82.

Blomquist, T. (1994) òTensions in Three Dimensions: A Method for Analyzing Problems in Renewal Projects.ò In: R. A. Lundin \& J. Packendorff (eds.) Proceedings of the IRNOP 
Conference on Temporary Organizations and Project Management: pp. 71-78. Umeå: IRNOP.

Borum, F \& Christiansen, J. K. (1993) òActors and Structure in IS Projects: What Makes Implementation Happen?ò Scandinavian Journal of Management, Vol. 9, No 1: pp. 528.

Briner, W. \& Geddes, M. (1990) òLinking Project Leadership to a Project Continuum: Different Types of Projects Require Leaders to Concentrate on Different Dimensions of Their Role.ò In: R. Gareis (ed.) Handbook of Management by Projects: pp. 317-325. Vienna: MANZ.

Buchanan, D. A. (1991) òVulnerability and Agenda: Context and Process in Project Management.ò British Journal of Management, Vol. 2: pp. 121-132.

Christensen, S. \& Kreiner, K. (1991) Projektledelse i løst koblede systemer: Ledelse og læring $\mathrm{i}$ en ufuldkommen verden [Project Management in Loosely Coupled Systems: Leadership and Learning in an Imperfect World]. Copenhagen: Jurist- og $\varnothing$ konomforbundets forlag.

Cleland, D. I. \& King, W. R. (1983) Systems Analysis and Project Management. New York: McGraw-Hill.

DiMaggio, P. J. \& Powell, W. W. (1983) òThe Iron Cage Revisited: Institutional Isomorphism and Collective Rationality in Organizational Fields.ò American Sociological Review, Vol. 40: pp. 147-160.

Dutton, J. E. (1993) òThe Making of Organizational Opportunities: An Interpretive Pathway to Organizational Change.ò Research in Organizational Behavior, Vol. 15: pp. 195-226.

Dutton, J. E. \& Duncan, R. B. (1987) òThe Creation of Momentum for Change through the Process of Strategic Issue Diagnosis.ò Strategic Management Journal, Vol. 8: pp. 279295.

Dutton, J. E.; Stumpf, S. A. \& Wagner, D. (1990) òDiagnosing Strategic Issues and Managerial Investment of Resources.ò Advances in Strategic Management, Vol. 6: pp. 143-167.

Ekstedt, E; Lundin, R. A. \& Wirdenius, H. (1992) òConceptions and Renewal in Swedish Construction Companies.ò European Management Journal, Vol 10, No 2: pp. 202-209.

Ekstedt, E. \& Wirdenius, H, (1995) òRenewal Projects: Sender Target and Receiver Competence in ABB ôT50ô and Skanska ôTâò Scandinavian Journal of Management, Vol. 11, No 4: pp. 409-421.

Engwall, M. (1992) òProject Management and Ambiguity: Findings from a Comparative Case Study.ò In: I. Hägg \& E. Segelod (eds.) Issues in Empirical Investment Research: pp. 173-197. Amsterdam: Elsvier Science.

Frame, J. D. (1994) The New Project Management: Tools for an Age of Rapid Change, Corporate Reengineering, and Other Business Realities. San Francisco: Jossey-Bass.

Granovetter, M. (1985) òEconomic Action and Social Structure.ò American Journal of Sociology, Vol. 91, No 3: pp. 481-510.

Gersick, C. J. G. (1988) òTime and Transition in Work Teams: Toward a New Model of Group Development.ò Academy of Management Journal, Vol. 31, No 1: pp. 9-41.

Hellgren, B. \& Stjernberg, T. (1995) òDesign and Implementation in Major Investments: A Project Network Approach.ò Scandinavian Journal of Management, Vol. 11, No 4: pp. 377-394.

Hodgetts, R. M. (1968) òLeadership Techniques in the Project Organization.ò Academy of Management Journal, Vol. 11, No 2: pp. 211-219.

Jessen, S. A. (1992) The Nature of Project Leadership. Oslo: Scandinavian University Press.

Kadefors, A. (1995) òlnstitutions in Building Projects: Implications for Flexibility and Change. ò Scandinavian Journal of Management, Vol 11, No 4: pp. 409-421.

Kreiner, K. (1995) òn Search of Relevance: Project Management in Drifting Environments.ò Scandinavian Journal of Management, Vol. 11, No 4: pp. 335-346.

Løwendahl, B. R. (1995) Òrganizing the Lillehammer Olympic Winter Games.ò Scandinavian Journal of Management, Vol. 11, No 4: pp. 347-362.

McElroy, W. (1996) òImplementing Strategic Change through Projects.ò International Journal of Project Management, Vol. 14, No 6: pp. 325-329. 
Midler, C. (1995) ơơrojectificationôof the Firm: The Renault Case.ò Scandinavian Journal of Management, Vol 11, No 4: pp. 363-375.

Morris, P. W. G. \& Hough, G. H. (1987) The Anatomy of Major Projects: A Study of the Reality of Project Management. Chichester: Wiley.

Packendorff, J. (1994) òTemporary Organizing: Integrating Organization Theory and Project Management.ò In: R. A. Lundin \& J. Packendorff (eds.) Proceedings of the IRNOP Conference on Temporary Organizations and Project Management: pp. 207-226. Umeå: IRNOP.

Packendorff, J. (1995) òlnquiring into the Temporary Organization: New Directions for Project Management Research.ò Scandinavian Journal of Management, Vol. 11, No 4: pp. 319-333.

Partington, D. (1996) òThe Project Management of Organizational Change.ò International Journal of Project Management, Vol. 14, No 1: pp. 13-21.

Pinto, J. K. \& Prescott, J. E. (1988) òVariations in Critical Success Factors Over the Stages in the Project Life Cycle.ò Journal of Management, Vol. 14, No 1: pp. 5-18.

Pinto, J. K. \& Prescott, J. E. (1990) òPlanning and Tactical Factors in the Project Implementation Process. ò Journal of Management Studies, Vol. 27, No 3: pp 305-327.

Pinto, J. K. (1996) Power and Politics in Project Management. Sylva, NC: Project Management Institute.

Turner, J. R. \& Cochrane, R. A. (1993) òGoals-and Methods Matrix: Coping with Ill Defined Goals and/or Methods of Achieving Them.ò International Journal of Project Management, Vol. 11, No 2: pp. 9310102. 